\title{
A Study on the Significance of Cypress, Plantain and Vine in Persian Culture, Art and Literature
}

Saba Alebrahim Dehkordi

Academic Member Art group of Payame Noor University

Email: saba_dehkordi@yahoo.com

\section{Shahram Taghipoor}

Department of Art, Faculty of Art and Architecture, Shahrekord Branch, Islamic Azad University, Shahrekord, Iran

Hamid Rezaei

Academic member of Persian literature group of Payame Noor University, Iran

Doi:10.5901/mjss.2015.v6n6s6p412

\section{Abstract}

Tree has always had a special place and holiness in different beliefs and cultures. In ancient times it was believed that holy trees could nourish and develop human and animal lives with their innate power and it was for this reason that they were praised. Persians also admired trees so much. From the trees which have secret and symbolic meanings with mythological powers for Persians; cypress, plane tree, grapevine and pomegranate can be named. Due to their symbolic meanings and secrets, these trees have always been significant for artists and literary people and specially poets during different eras. In the present research the authors have a panoramic view to the history and role of cypress, plane tree and grapevine in the art, culture, and literature of the people of Persia.

\section{Keywords: cypress, plantain and vine, Persian Culture}

\section{Introduction}

Generally the universe has a life in the view of primitive people and in this regard plants and trees are no exception. They believed that plants and trees are in possession of souls and they treated them based on this thought. In mythological analyses, human species is attributed to the origin of life which is found in various plants (Eliade, 1993).

In Animism which believes in the idea that natural non-human entities possess a spiritual essence independently of their own, there is the supposition that these spirits can have a role in the fate of human beings. There is an inclination in human beings that includes everything in their own species and thus makes descriptions for objects which are actually related to themselves as human beings (Freud, 1983).

If trees have life, it shows that they are sensitive and the act of cutting them turns into a meticulous operation which must be done with minute care and delicacy no to harm the tree. Otherwise it is possible that the tree come back and retaliate in which it would kill the careless person (Frazer, 2009).

From all the beautiful mythological legend about plants, there follows the conclusion that tree is a god-given blessing. Wise people should have respect for the world of plants and this godly system and abstain from harming and cutting trees (Rangchi, 2010).

\section{Plants and Trees in the View of Ancient Persians}

According to ancient Persian system of codes related to the beginning of creation, the sky is the first material creation, then water and the earth in the second and third place and plants in the fourth one in terms of existence. But according to the tradition of Persian poetry which has originated from the thoughts of old thinkers of Persia, India and vast eastern civilizations, the four levels of existence are made up of non-living entities, plants, animals and human beings. It is seen that after the creation of the four elements and the seven skies, non-living entities, plants and animals appear in Persian writings. Ferdowsi, in the introduction to his Shahnameh, believes that the statuses of existence have originated from the 
four elements. He believes in the precedence of the creation of the sky to the earth, followed by mountains and then plants, animals and human beings (Ferdowsi, 1994).

The mythical significance of tree among Persians can be understood by the story of the creation of the first human parents who are called Mashi and Mashiane. The first human couple rose out of Keyumars from the earth. In the beginning they nourished like a plant intertwined in each other in a way that distinguishing the male from the female was not possible. These two created a tree which was comprised of ten races of mankind. Finally when they got the human form, Ourmazd taught them their responsibility (Hinnells, 1989).

Ancient Persians revered trees so much that sometimes they liked them to the point of worship. Gaining respect of some of evergreen or old trees in Persia in their vicinity to holy shrines and respected people is the sign of the holiness of plants in the beliefs of Persians (Bahar, 1997).

\section{Symbolic Role of Plants in Arts and Literature}

Language of symbols and secrets as a universal and comprehensible language for all human beings, have the will to creation of unity and elimination of pluralities and with an educative operation creates a connection between the inside and the outside world of mankind. A world without symbols is a suffocating world and it will result in the spiritual death of human beings. Plants and vegetal elements in their secret and symbolic forms are representatives of the connection between the material world to the other spiritual ones and topics like levels of existence and the universe, plant nature of human beings, metamorphosis in the form of vegetal imageries, ritual afterlife of plants, myth of the world tree, religious trees etc. are all characteristic of the mixture of human worlds with natural (plant) worlds and show the connection between spirit to the other world (Zomorrodi, 2008).

An old tree or plant is the symbol of nourishment and development of mental life. This is the reason that vegetal elements contain secrets and symbols which manifest something more elevated than mere implications and even

More than their implicated meanings and in fact they connect the human soul to the utmost levels of existence. Poets are always willing to have an unconscious emotional participation with natural phenomena and the inclination to ancient remains or eternal archetypes make it easier to approach the spirit of nature in mankind and result in some kind of a mutual life between human beings and natural elements. In the vegetal imageries of poets, the use of vegetal elements has created a different level in comprehension of speakers and this shows the continuity of secrets and symbols in ancient and modern Persian poetry. Symbol is the production of nature and based on the principles of the school of Naturalism, the amalgamation and conveying of feelings in the field of natural elements with metaphysical senses are the creators of thoughts which are connected mutually to the internal part and the external (natural) form of the individual. And this is the reason that poets describe the beauties of nature and imitate its existing forms.

Mankind is a creature that has roots in soil like plants, but her/his beginning is tied to the sky. Plants as heavenly and holy symbols have also the capability of stimulating the mythical conscience in relation to the connection that exists with God. The empathy of human beings to vegetal nature in the light of symbols and secrets has its roots in natural, vital and epistemic tendencies of the individual and through this symbolic and hidden elements form in our literature and especially in poetry. Tree has always been an example and a symbol of rebirth, revitalization and return to a specific source. It has been thought like a thorough mirror manifesting mankind and a unique notion in the genealogy of human beings.

The biggest otherworldly secret of trees is the heavenly tree which has its roots in the upper and other world like human beings and is the reminder of connection to heaven and communication with God. According to the theory of race connections and empathy of human beings to plants in Persian poetry, we are faced with examples and beliefs which hold the idea that plants are the manifestation and incarnation of life and the symbol of rebirth. The periodic rebirth of plants in the light of the continuing growth of them is reminiscent of the myth of eternal return to a unique source (Sattari, 1988). And this means that human beings and plants are willing to reach their original source and rebirth.

Mankind has always felt a kind of father and son relationship with trees and according to some of the human tribes is in possession of several spirits that one of them is under the control of plants. Because of this reason, among natural manifestations, tree is the incarnation of the genealogy and symbol of nourishment in the mental development of human beings. The poet of Tus, Ferdowsi has also used tree as the sign of the representation of vegetal genealogy:

I don't want any tree from Siyawush

No branch, no leaf, no crown and no throne (Ferdowsi, 1994).

Bahram told him that you are lucky

To be the forbearer to the tree of monarchy (Ferdowsi, 1994). 
Plant samples on clays, seals and stones are found from ancient Persia. Elamite world or the Persian world is full of works based on plants which are the epicenter and source of tree like gunmetal works in Lorestan, Marlik and Ziviye. During the time of Indo-Iranians, Medians, Achaemenids and Parthians the ritual image of tree is still noticeable (Javani, 2000).

Also during the third and fourth century after Islam i.e. the era of Samanids, the role and symbol of tree has remained in all aspects of art in the period. In Persia so many trees like grapevines, plane trees, and willow trees have been supposed to be holy and among them cypresses were the symbol of life during those times and the role of this kind of tree has been used symbolically in all the arts and literature from then to the present time.

\subsection{Cypress (Cupressus Sempervirens)}

The scientific name of cypress has originated from the ancient Greek term which is made up of kuo meaning production and pariso meaning equal in relation to the symmetry of leaves and the crown of the tree (Sabeti, 2006). It has been popular that cypress is the name of a famous tree which has three types; one is Azad cypress, the other one Sahi cypress and the third one Naz cypress. Arabs call cypress by the name of Shajarat-al-Hayyah or the tree of snake because they believed that wherever it grew there would be snakes in the vicinity. Due to the fact that cypress and olive tree are evergreen trees, they are believed to come from paradise (Masse, 1974). Cypress is the sign of eternality and immortality. Because of its long life and being green all the time, it has been called as the tree of life and among trees it has a powerful mythological feature.

Probably it was because of its holiness or value that cypress was included in girls' dowries. The sign that is seen in cashmere shawls and textile printings in traditional paisley designs in Isfahan is in the form of a cypress tree which has its top inclined to one direction because of the wind that is blowing and this is significant in the sense that it shows that during old times people focused on this kind of tree. The cypress standing strongly has been viewed as holy from ancient times among Persians. Cypress tree is also the symbol of the positive and amusing aspect of the spirit and of religious life. Because of this fact there is a plethora of cypress trees in holy places in Iran. Some people hold that every tree has a high and flourishing point and a downward one in which sometimes they possess so many leaves and in other times they are forlorn and without leaves. But none of these exist in cypress trees for they are always green and because of this they are the symbol of freedom and people who gained their freedom. Cypress grows directly and in one line upwardly and because it does not go into other trees in the vicinity, it is called a free tree. According to some, the attribution of freedom and unboundedness to cypress is reminiscent of its affinity to Nahid which is the symbol of freedom in mythology and also the fact that every tree that does not bear fruits is believed to be free. Cypress has been used in various Persian arts like painting, handicraft and architecture from ancient times. The symbolic role of cypress has had a continuous part in Iranian painting. In Persepolis and Achemenid palaces, cypress was among the major signs and the symbol of Ahura Mazda. Among other handmade arts like carpeting the role of cypress is significant.

\subsection{Cypress of Kashmar}

The biggest cypress tree which has existed in Iran has its descriptions in Shahnameh telling that the Zoroastrian prophet of Persia planted the seed of a magnificent cypress and it had enormous dimensions and great features (Coyajee, 1999). Ferdowsi also believed in cypress of Kashmar as being the Qibla of Zoroastrians. This type of cypress is famous in Persian literature as it was described as a heavenly tree that grows to the extreme point where according to sayings it covers more than ten thousand sheep in its shade and numerous birds sitting on its branches.

There is in Shahnameh that this tree was planted near the entrance of the fire temple and Gashtasb built a massive hall around this cypress. According to the way that this hall is described in Shahnameh, some see a correspondence to the temple of the sun in Heliopolis in Egypt. Cypress of Kashmar lived for ages until it was cut by the order of the Abbasid caliph Al-Motevakkel. The age of this tree according to some calculations was one thousand four hundred and five in the time of its cutting. Because of reasons and people's beliefs about cypress, this tree has always been interesting for poets and literary people and by using the attributions directed to this tree, poets have had beautiful descriptions of nature and human beings. In Persian poetry and literature in general, numerous descriptions have been used in relation to cypress like truthful, standing, strong, rebellious, fresh, young, rising, honorable, straight, committed, pure and indigent. Also in many other cases, cypress is a metaphor for the body of the beloved and in this case terms like well-rounded, shining, delicate, fresh, smooth, affable, etc. are used. 


\subsection{Plane Tree (Platanus Orientalis Known as Chenar)}

Plane tree is one of the biggest and oldest types of trees in Iran. It is the name of a tall tree which is famous for its old age and burning by itself by fire. According to this idea, it burns by itself in a way that it is believed it creates fire through its own materials. This idea has also been used in poetry.

\section{If water is stopped for Chenar}

Be sure there will be fire by itself.

Plane tree peels its bark every year and its branches get a fresh green color as a result. Its rejuvenation grants a special holiness to it because preserving the power of youth is one of the conditions which necessitate reproduction and as a result it is believed to be the symbol of eternal blessing of gods and spirits. Plane tree is the symbol of glory and edification in Persian culture. Glorious ceremonies and singing rituals are held in the shade of plane trees through Persian images. In ancient Persia, plane tree has been the representation of affluence, fertility and flourish of nature and the cause of gods' and spirits' blessings. When Darius the Great was in Asia Minor, he was granted a grapevine and a golden plane tree which it was mostly put in the king's room.

Plane tree is the symbol of the king and grapevine was the symbol of the queen that through him the royal blood would persist. The mass of people believe that plane tree is the king of trees and they also believe that old plane trees bring blessing and rich harvests to the field and family and they sustain fertility and health in women thus plane trees are called the "tree of purpose" because of the idea of fertility and the chance of helping having children. The leaf of plane tree is compared to the palm of the hand in Persian poetry.

\subsection{Grapevine}

According to Epistle of Nowruz or Nowruznameh, the seed of grapevine was planted in the time of one of the kings from Jamshid's line called Shemiran. In Persian mythology, grapevine is the symbol of blood which is a major power.

The oldest historical account of grapevine is from Herodotus who states; The last king of Medes saw his daughter who would later become the mother of Cyrus in a dream in which a grapevine grew from her abdomen and spread all over Asia. In most of ancient writings, grapevine is mentioned along plane tree because of the reason that plane tree is the symbol of a king and grapevine is the symbol which represents everything about the king i.e. his whole entirety. The intertwining of grapevine and plane tree is the sign of the continuity of monarchy through blood.

Grapevine has gained a special significance in Persian literature; particularly in its relation to wine and it has created new and different concepts in the minds of the poets. Some of the poets have composed Qasida or Chakameh in description of grapevine to the extent in which these types of poems got famous as a genre called Khamriyya or the wine poem in Persian literature.

In the field of Islamic arts, the role of arabesque is believed to be the abstraction and extraction of tree and particularly grapevine being under the influence of the art of the Sassanid period and has its roots in the tree of life which has a very ancient background in Persian art and beliefs. The cluster icon of grape, branch and leaves of grapevine are seen in Persian artistic productions like Persian carpets.

\section{Conclusion}

The idea of considering symbolic examples and then producing them is one of the most obvious ways of human struggle which gives meaning to symbols while having observations based on their formal aspects including various meanings relying on basic beliefs of a society. Holy trees are samples within the social life of Iranians from past to the present which have given them the opportunity and possibility of the formation of beliefs through rituals, social behaviors and artistic attitudes. Trees like cypress, chenar and grapevine are among the holiest ones in the beliefs of the people of this country. Each of them is a special symbol and has its own sign. In addition to their formal features, these trees are in a way a mental understanding of nature and possess symbolic significance. Discussion over Persian myths shows that these trees have meaning in relation to ideas about blessing and giving of life and as a result the Persian artist and literary person have been creating works by using them from past to the present and will use them in the future. 


\section{References}

Eliade, M. (1993). Traite d'histoire des religions. First Publication. (pp. 288-304).Tehran: Soroush Publication.

Freud, S. (1983). Totem and Taboo. First Publication. (pp. 130-135).Tehran: Asia Publication.

Frazer, J.G. (2009). The Golden Bough. (pp. 155-159).Tehran: Agah Publication.

Rangchi, G. (2010). Plants and Flowers in Persian Poetry until the Beginning of Mogul Era. (pp. 8-15).Tehran: Institute for Humanities and Cultural Studies.

Ferdowsi, Q. (1994). Shahnameh. Edited by: Hamidian S. Vol. 1, 15, 16. (pp. 288-304).Tehran: Ghatreh Publication.

Hinnells, J.R. (1989). Persian Mythology. Edited by: Ahmad Tafazzoli, A. \& Amouzgar, J. (pp. 93-95). Babol: Cheshmeh Publication.

Bahar, M. (1997). From Myth to History. Edited by: Esmailpour, A. (pp. 261-265).Tehran: Cheshmeh Publication, 1997.

Zomorrodi, H. (2008). Vegetal Symbols and Secrets in Persian Poetry. First Publication. (pp. 16-20).Tehran: Zavarbook Publication.

Sattari, J. (1988). Sign Thinking and Heavenly Art. (pp. 21-28).Tehran: Markaz Publication.

Javani, A. (2000). Art and Symbol (Tree). Number 7. (pp. 32-35).Tehran: Honarnameh.

Sabeti, H. (2006). Forests, Trees and Shrubs of Iran. (pp. 296-300).Yazd: Yazd University Publication.

Masse, H. (1974). Croyances et Coutumes Persanes. Edited by: Roshanzamir, M. Vol. 1. (pp. 243-254). Tabriz:Institute of Iranian History and Culture, Tabriz University.

Coyajee, J.C. (1999). Continuity of Persian and Chinese Legends. Edited by: Koushya Karimitari. (pp. 34-42).Tehran: Naslenow Andish Publication. 